\title{
PREDICTION OF ACTIVITY SPECTRA OF SUBSTANCES ASSISTED PREDICTION OF BIOLOGICAL ACTIVITY SPECTRA OF POTENTIAL ANTI-ALZHEIMER'S PHYTOCONSTITUENTS
}

\author{
ABHINAV ANAND, NEHA SHARMA, NAVNEET KHURANA* \\ Department of Pharmacology, School of Pharmaceutical Sciences, Lovely Professional University, Punjab, India. \\ Email: navi.pharmacist@gmail.com
}

Received: 14 July 2017, Revised and Accepted: 25 July 2017

\begin{abstract}
objective: Alzheimer's disease (AD) is a neurodegenerative disorder that is associated with loss of memory and cognition. It is responsible for $60-80 \%$ of dementia cases. The current pharmacotherapy provides only symptomatic relief. There is an urgent need for discovery and development of newer drugs that could delay or halt the progression of disease. Prediction of activity spectra of substances (PASS) is a valuable interface that should be adopted as a quintessential tool for predicting potential anti-AD capability of molecules.
\end{abstract}

Objective: To predict the biological activity of certain phytoconstituents for their anti-AD effects.

Methods: Several phytoconstituents were selected on the basis of reported literature. The anti-AD activities of selected phytoconstituents were predicted by employing canonical simplified molecular-input line-entry system obtained from PubChem using PASS online.

Results: Several phytoconstituents were predicted to have effects better than marketed drugs under some or the other out of the chosen six areas of pharmacological intervention. On the other hand, several new avenues were predicted in which the in vitro and in vivo evaluation of the phytoconstituents can be made on the basis of PASS predicted activities.

Conclusion: PASS is an important tool for virtually screening the compounds of interest for the biological activities of interest. This helps the researchers to streamline the research. However, PASS has its own share of limitations amidst a multitude of merits.

Keywords: Alzheimer's disease, Prediction of activity spectra of substances, Phytoconstituents, Prediction.

(C) 2017 The Authors. Published by Innovare Academic Sciences Pvt Ltd. This is an open access article under the CC BY license (http://creativecommons. org/licenses/by/4. 0/) DOI: http://dx.doi.org/10.22159/ajpcr.2017.v10is4.21330

\section{INTRODUCTION}

Alzheimer's disease (AD) has been recognized as the most prevalent form of dementia among geriatric persons since the commencement of $21^{\text {st }}$ century. Over 47.5 million people globally were estimated to be living with dementia in 2016. By 2030, the figure is being speculated to rise to 75.6 million [1]. AD is a neurodegenerative disorder that generally appears in mid-to-late adulthood. It is associated with a progressive and rather irreversible decline in memory various other cognitive capabilities. In AD, there is neuronal destruction and deterioration of neural connections in the cerebral cortex region of the brain along with a substantial loss of brain mass [2]. AD is invariably progressive and lethal within 5-10 years of its onset [3]. Death usually ensues due to complications of the chronic illness. It is one of the top five most common causes of mortality in population of the United States [4]. In some rare cases, it appears in people in their 40 seconds and 50 seconds, but otherwise it is a disease of old age. Based on clinical, population-based studies, about 200,000 people under 65 years of age are suffering from AD. In contrast, around 5 million of those over 65 years of age have AD. As per speculations, a new case of $\mathrm{AD}$ is expected to be developed every 33 seconds, by 2050 [5].

$\mathrm{AD}$ is characterized by the presence of two neuropathological hallmarks, i.e., extracellular amyloid beta plaques $(A \beta)$ and intracellular Tau neurofibrillary tangles (NFTs). The plaques constitute chiefly of the neurotoxic peptide amyloid, which forms after the sequential cleavage of a large precursor protein, i.e., amyloid precursor protein (APP) by two enzymes, namely, $\beta$-secretase and $\gamma$-secretase. However, $A \beta$ is not formed if APP is first acted upon and cleaved by the enzyme $\alpha$-secretase instead of $\beta$-secretase. NFTs comprise mainly of the protein tau. In the development of $\mathrm{AD}$, Tau uncouples from microtubules and aggregates into tangles thereby inhibiting transport and resulting in microtubule disassembly. It also depends on the phosphorylation of Tau (Fig. 1) [6].

The current pharmacotherapeutic approaches for AD provide only symptomatic relief. There is an urgent need for discovery and development of new drugs that could halt or delay the progression of disease by treating the underlying causes $[7,8]$. The new drug development is a very tedious process and is associated with high probability of negative results in terms of pharmacological efficacy. In such a scenario, it becomes imperative that a tool should be available which could predict the pharmacological properties beforehand. It would enable the researchers to streamline the research more efficiently. Prediction of activity spectra of substances (PASS) is such a tool which can predict the pharmacological properties beforehand and would help in screening pharmacological potential leads for a particular condition [9].

Plant sources have been an integral part of traditional medicine systems since ages, be it the Traditional Indian Medicine System or Traditiona Chinese Medicine System. Around 70\% of New Chemical Entities which later became drugs between the periods of 1981-2006 originated from plant sources [10]. Screening of molecules virtually is of specific importance to form basis of pharmacology and receptor interactions for phytoconstituents [11].

The applicability of PASS to phytoconstituents has been exhibited in earlier investigations [12-14]. The current version of PASS is capable of predicting over 3750 biological effects, biochemical modes of action, specific toxicities, and metabolic terms based on 2D structures or canonical simplified molecular-input line-entry system (SMILES) with a mean accuracy of almost 95\%. It predicts 
the spectra of biological activities for a molecule in terms of probable activity $(\mathrm{Pa})$ and probable inactivity $(\mathrm{Pi})$. This prediction is based on the analyses of structure activity relationship of the training set comprising of over 2,05,000 compounds showing over 3,750 kinds of biological activities. The present study incorporates the use of PASS for exploration of the pharmacological potential of selected phytoconstituents in treatment of $\mathrm{AD}$ with respect to various disease associated targets.

\section{MATERIALS AND METHODS}

\section{Materials}

Several phytoconsitutents were selected on the basis of existing literature suggesting their applicability in treatment of AD (references mentioned in Table 1). Three marketed drugs for treatment of AD were also selected to be analysed for prediction of biological activity spectra. The canonical SMILES of these phytoconstituents and marketed drugs were obtained from PubChem (www.pubchem.ncbi.nlm.nih.gov) as in Table 2 .

\section{Methods}

An elaborate search of existing literature was conducted to collect information pertaining to the previously reported biological activities, both in vitro and in vivo, of these phytoconstituents. The biological activity spectra of these phytoconstituents were obtained by Canonical SMILES using PASS online available from www.pharmaexpert.ru/ passonline/predict.php/.

The PASS prediction results were interpreted in the following manner: (i) Only the activities for which $\mathrm{Pa}>\mathrm{Pi}$, i.e., higher $\mathrm{Pa}$, have been taken

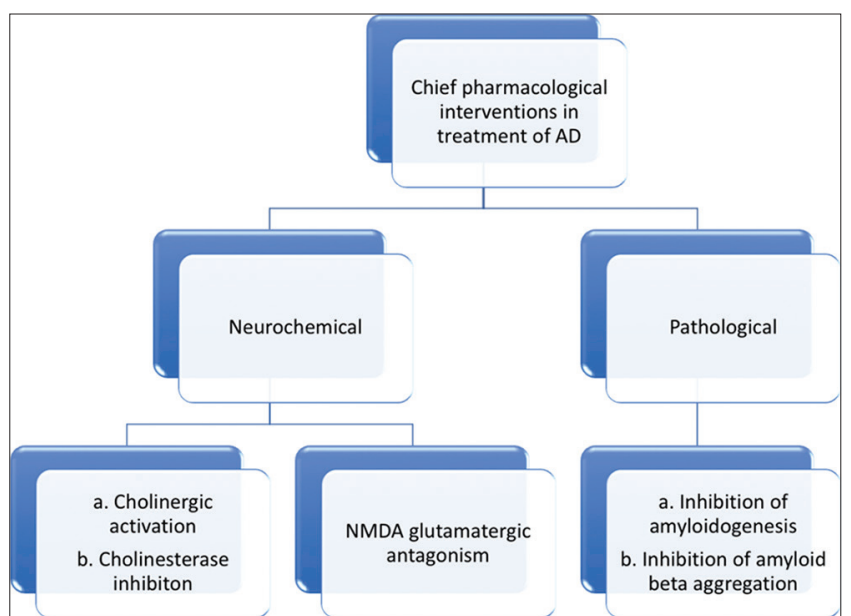

Fig. 1: The chief pharmacological interventions in treatment of Alzheimer's disease into account for each phytoconstituent, (ii) if $\mathrm{Pa}>0.7$, the probability to obtain a similar activity experimentally is appreciably high; hence, it is the chance of it being an analogue of an existing drug, (iii) if 0.5 $<\mathrm{Pa}<0.7$, the probability to obtain a similar activity experimentally is relatively less and the substance is likely to be dissimilar from the existing pharmaceutical agents, (iv) if $\mathrm{Pa}<0.5$, the probability to find the activity experimentally is lesser, but the probability of finding a new, structurally similar compound (NCE) is more [15]

\section{RESULTS}

The selected marketed drugs and potential phytoconstituents were analyzed using PASS assisted prediction for six AD-related areas of pharmacotherapeutic intervention. The considered AD-related areas are as follows: (i) Cholinergic activity (including acetyl cholinesterase inhibition, butyrylcholinesterase inhibition, acetylcholine release stimulation), (ii) antiamyloidogenic activity (including $A \beta$ antagonism and APP antagonism), (iii) anti-A $\beta$ aggregatoryactivity, (iv) antidementia activity, (v) nootropic activity, and (vi) glutamate antagonistic activity (including glutamate release inhibition). The results obtained have been presented in Table 1.

Fig. 2 shows the relative cholinergic activity of the selected phytoconstituents with respect to the marketed drugs for AD. Fig. 3 shows the relative antiamyloidogenic activity of the selected phytoconstituents with respect to the marketed drugs for AD. Fig. 4 shows the relative anti-A $\beta$ aggregatory activity of the selected phytoconstituents with respect to the marketed drugs for AD. Fig. 5 shows the relative antidementia activity of the selected phytoconstituents with respect to the marketed drugs for AD. Fig. 6 shows the relative nootropic activity of the selected phytoconstituents with respect to the marketed drugs for AD. Fig. 7 shows the relative glutamate antagonistic activity of the selected phytoconstituents with respect to the marketed drugs for AD. Phytoconstituents for which $\mathrm{Pa}$ value was not predicted (under respective areas of pharmacological interventions) have not been included in the figures.

\section{DISCUSSION}

PASS is an online interface which allows for a hassle-free registration at no charge. The software predicts the biological activities of compounds by three tools - canonical SMILES, MOL files, and an inbuilt JAVA applet for drawing 2D structures (MarvinSketch). The biological activity spectra for an enormous number of molecules can be predicted by PASS in a very short period of time.

The marketed drugs and the selected phytoconstituents were analyzed for their anti-AD potential on the basis of PASS prediction. The analysis was done under six areas of pharmacological intervention and the obtained results in the terms of Pa values have been summarized in Figs. 8 and 9.

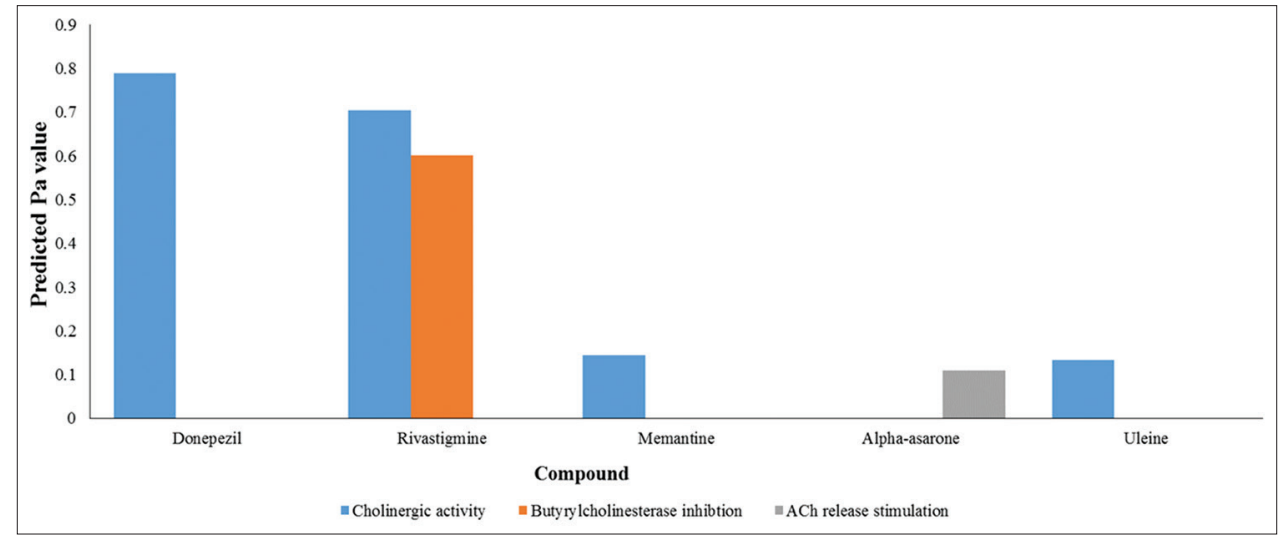

Fig. 2: Relative cholinergic activity of selected compounds 


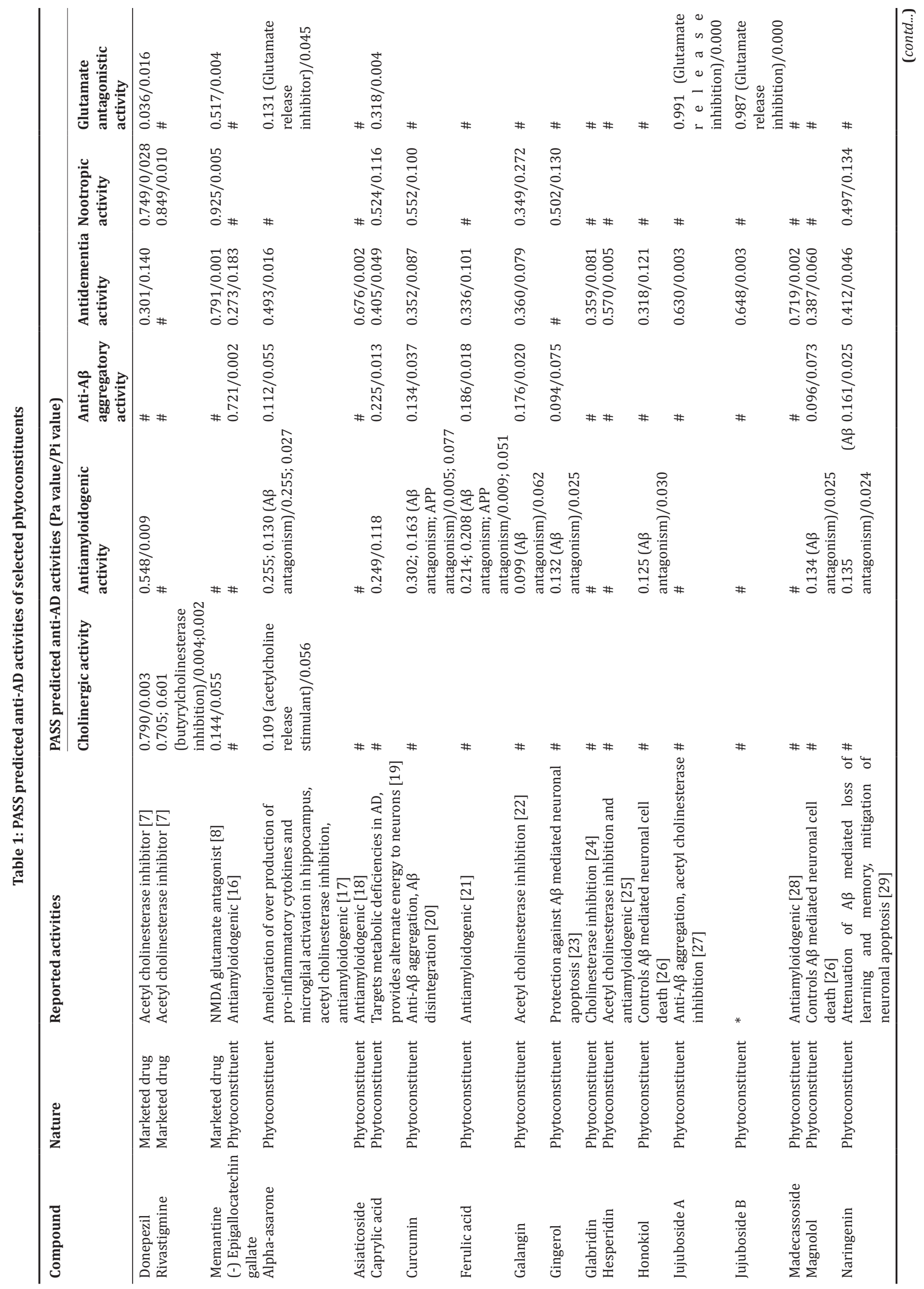


While the selected phytoconstituents did not exhibit a significant predicted cholinergic activity as compared to the marketed drugs, alpha-Asarone was predicted to have a stimulant effect on ACh release and Uleine was predicted to have some cholinergic activity.

Vanillin was predicted to have antiamyloidogenic activity more than marketed drug donepezil. The antiamyloidogenic potential was also predicted in curcumin, resveratrol, alpha-Asarone, caprylic acid, ferulic acid, magnolol, and honokiol (in a decreasing order of Pa values). Almost negligible Pa value for antiamyloidogenic effect was predicted for galangin. Some compounds were also predicted to have an $A \beta$ antagonistic effect. Ferulic acid was predicted to have the maximum antagonistic effect on the $A \beta$ protein followed by curcumin, resveratrol, naringenin, gingerol, and alpha-Asarone.

Many selected phytoconstituents were predicted to have an anti-A $\beta$ aggregatory activity which was predicted to be absent in all the three chosen marketed drugs (donepezil, rivastigmine, and memantine). $(-)$ Epigallocatechin gallate - the green tea polyphenol, was predicted to have a remarkable anti- $\mathrm{A} \beta$ aggregatory activity. Resveratrol, caprylic acid, ferulic acid, galangin, naringenin, curcumin, vanillin, and alpha-Asarone. Almost negligible activity was predicted for effect on aggregation of $A \beta$ for magnolol and gingerol.

Madecassoside was predicted to have maximum effect against dementia followed by asiatacoside, Jujuboside B, Jujuboside A, hesperidin, alpha-Asarone, resveratrol, vanillin, naringenin, caprylic acid, magnolol, galangin, glabridin, curcumin, ferulic acid, and honokiol. The predicted Pa values of these phytoconstituents were higher than that of donepezil. Milder antidementia effect was predicted for uleine and (-) Epigallocatechin gallate as well. However, none of the selected phytoconstituents was predicted to have an antidementia activity higher than Memantine but the predicted Pa value of Madecassoside is in close range of the marketed drug.

Curcumin, caprylic acid, gingerol, naringenin, resveratrol, and galangin were predicted to have a nootropic activity. However, the predicted $\mathrm{Pa}$ values for these phytoconstituents were lesser than memantine, rivastigmine, and donepezil.

Jujubosides A and B were predicted to have a significant inhibitory effect on release of glutamate which was predicted to be absent in the marketed drugs. Resveratrol and alpha-Asarone were also predicted to inhibit glutamate secretion to a small extent. Caprylic acid was predicted to have a glutamate antagonistic effect more than donepezil but less than Memantine.

PASS helps in choosing and optimizing the compounds, based on the structure of predicted target site of interest for computer aided drug design and enables the chemists to speed up the process. It is a very beneficial tool for revealing novel modes of action of existing molecules. It helps in finding new lead compounds which can be further optimized. The chief benefit is the software's capability to predict a wide array of biological activities in a nominal amount of time.

The predicted $\mathrm{Pa}$ and $\mathrm{Pi}$ values are not conclusive in terms of the biological activity of the molecule as it makes the predictions on the basis of 2D structure of the molecule. In addition, it does not consider the energy levels of the molecules. However, owing to these drawbacks of PASS, it can happen that the predicted activities may notbe practically reported or observed in vivo and the activities not predicted through PASS may be practically observed in different pharmacological tests. For example, hesperidin has been reported to have acetyl cholinesterase inhibitory and antiamyloidogenic activities in previous in vivo studies while both these effects have not been predicted by PASS. Similarly, Jujuboside A has not been reported in the previous in vivo study to have glutamate antagonistic effect, but PASS has made a significant prediction of this effect. 
Table 2: Selected molecules/compounds for PASS prediction with respective canonical SMILES

\begin{tabular}{l}
\hline Molecule/Compoun \\
\hline Donepezil \\
Rivastigmine \\
Memantine \\
\\
(-) Epigallocatechin \\
gallate
\end{tabular}

gallate

Alpha-Asarone

Asiaticoside

Caprylic acid

Curcumin

Ferulic acid

Galangin

Gingerol

Glabridin
CCN (C) C(=0) OC1=CC=CC(=C1) C (C) N (C) C

CC12CC3CC (C1)(CC (C3)(C2) N) C

C1C (C (OC2=CC $(=\mathrm{CC}(=\mathrm{C} 21)$ 0) 0$) \mathrm{C} 3=\mathrm{CC}(=\mathrm{C}(\mathrm{C}(=\mathrm{C} 3)$ 0) 0$)$ o) OC $(=0)$ $\mathrm{C} 4=\mathrm{CC}(=\mathrm{C}(\mathrm{C}(=\mathrm{C} 4) 0) \mathrm{O}) \mathrm{O}$

$\mathrm{CC}=\mathrm{CC} 1=\mathrm{CC}(=\mathrm{C}(\mathrm{C}=\mathrm{C} 10 \mathrm{OC}) \mathrm{OC}) \mathrm{OC}$

CC1CCC2(CCC3(C $(=\mathrm{CCC} 4 \mathrm{C} 3(\mathrm{CCC} 5 \mathrm{C} 4(\mathrm{CC}(\mathrm{C}(\mathrm{C5}(\mathrm{C}) \mathrm{CO})$ 0) O) C) C) C2C1C) C) $\mathrm{C}(=0)$ 0C6C (C (C (C (06) Coc7C (C (C (C (O7) CO) 0C8C (C (C (C (O8) C) O) O) 0) 0) 0) 0) 0) 0

$\operatorname{CCCCCCCC~}(=0) 0$

$\operatorname{coc} 1=\mathrm{C}(\mathrm{C}=\mathrm{CC}(=\mathrm{C} 1) \mathrm{C}=\mathrm{CC}(=0) \mathrm{CC}(=0) \mathrm{C}=\mathrm{CC} 2=\mathrm{CC}(=\mathrm{C}(\mathrm{C}=\mathrm{C} 2)$ 0) OC $) \mathrm{O}$

$\operatorname{coc} 1=C(C=C C(=C 1) \mathrm{C}=\mathrm{CC}(=0) 0) 0$

$\mathrm{C} 1=\mathrm{CC}=\mathrm{C}(\mathrm{C}=\mathrm{C} 1) \mathrm{C} 2=\mathrm{C}(\mathrm{C}(=\mathrm{O}) \mathrm{C} 3=\mathrm{C}(\mathrm{C}=\mathrm{C}(\mathrm{C}=\mathrm{C} 302) \mathrm{O}) \mathrm{O}) \mathrm{O}$

$\operatorname{CCCCCC}(\operatorname{CC}(=0) \operatorname{CCC} 1=\operatorname{CC}(=\mathrm{C}(\mathrm{C}=\mathrm{C} 1) 0)$ OC $) 0$

$\mathrm{CC} 1(\mathrm{C}=\mathrm{CC} 2=\mathrm{C}(\mathrm{O} 1) \mathrm{C}=\mathrm{CC} 3=\mathrm{C} 2 \mathrm{OCC}(\mathrm{C} 3) \mathrm{C} 4=\mathrm{C}(\mathrm{C}=\mathrm{C}(\mathrm{C}=\mathrm{C} 4)$ 0) 0$) \mathrm{C}$
Chemical structure<smiles>COc1cc2c(cc1OC)C(=O)C(CC1CCN(Cc3ccccc3)CC1)C2</smiles><smiles>CCN(C)C(=O)Oc1cccc(C(C)N(C)C)c1</smiles><smiles>CC12CC3CC(C)(C1)CC(N)(C3)C2</smiles><smiles>C=C(CC1c2ccc(C)cc2Cc2cc(O)ccc21)c1cc(C)c(C)c(C)c1</smiles><smiles>C/C=C/c1cc(OC)c(OC)cc1OC</smiles>

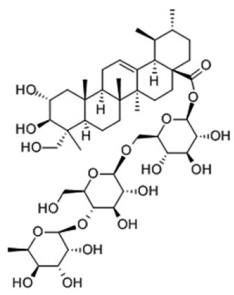<smiles>CCCCCCCC(=O)O</smiles><smiles>CC1CCC(CCC(=O)CCCC2CCC(C)C(C)C2)CC1</smiles><smiles>COc1cc(/C=C/C(=O)O)ccc1O</smiles><smiles>O=c1c(O)c(-c2ccccc2)oc2cc(O)cc(O)c12</smiles><smiles>CCCCCC(O)CC(=O)CCc1ccc(O)c(OC)c1</smiles><smiles>CC1(C)C=Cc2c(ccc3c2OCC(c2ccc(O)cc2O)C3)O1</smiles> 
Table 2: (Continued)

\begin{tabular}{|c|c|c|}
\hline Molecule/Compound & Canonical SMILES (obtained from PubChem) & Chemical structure \\
\hline Hesperidin & $\begin{array}{l}\mathrm{CC} 1 \mathrm{C}(\mathrm{C}(\mathrm{C}(\mathrm{C}(\mathrm{O} 1) \text { OCC2C }(\mathrm{C}(\mathrm{C}(\mathrm{C}(\mathrm{O} 2) \text { OC3=CC }(=\mathrm{C} 4 \mathrm{C}(=0) \mathrm{CC}(\mathrm{OC} 4=\mathrm{C} 3) \\
\mathrm{C} 5=\mathrm{CC}(=\mathrm{C}(\mathrm{C}=\mathrm{C} 5) \text { OC) 0) 0) 0) 0) 0) 0) 0) } 0\end{array}$ & $\mathrm{OH} \mathrm{O}$ \\
\hline Honokiol & $C=C C C 1=C C(=C(C=C 1) 0) C 2=C C(=C(C=C 2) 0) C C=C$ & \\
\hline Jujuboside A & 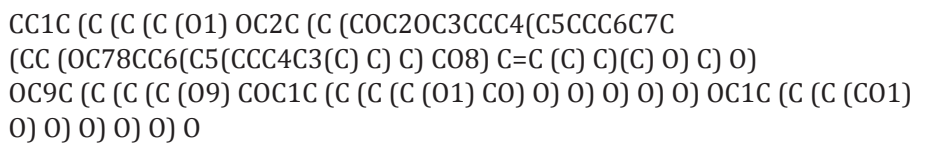 & \\
\hline Jujuboside B & 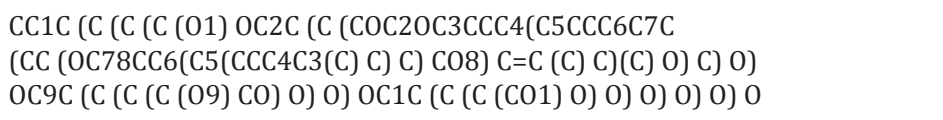 & \\
\hline Madecassoside & 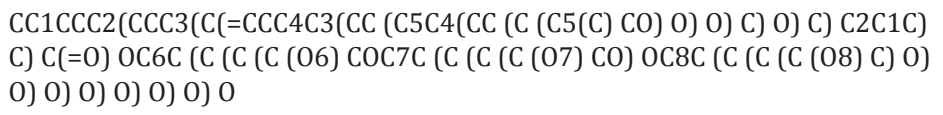 & \\
\hline Magnolol & $\mathrm{C}=\mathrm{CCC} 1=\mathrm{CC}(=\mathrm{C}(\mathrm{C}=\mathrm{C} 1) \mathrm{0}) \mathrm{C} 2=\mathrm{C}(\mathrm{C}=\mathrm{CC}(=\mathrm{C} 2) \mathrm{CC}=\mathrm{C}) \mathrm{O}$ & \\
\hline Naringenin & $\mathrm{C} 1 \mathrm{C}(\mathrm{OC} 2=\mathrm{CC}(=\mathrm{CC}(=\mathrm{C} 2 \mathrm{C} 1=0) 0) 0) \mathrm{C} 3=\mathrm{CC}=\mathrm{C}(\mathrm{C}=\mathrm{C} 3) \mathrm{O}$ & \\
\hline Resveratrol & $\mathrm{C} 1=\mathrm{CC}(=\mathrm{CC}=\mathrm{C} 1 \mathrm{C}=\mathrm{CC} 2=\mathrm{CC}(=\mathrm{CC}(=\mathrm{C} 2) 0) 0) \mathrm{O}$ & \\
\hline Uleine & $\mathrm{CCC} 1 \mathrm{C} 2 \mathrm{CCN}(\mathrm{C} 1 \mathrm{C} 3=\mathrm{C}(\mathrm{C} 2=\mathrm{C}) \mathrm{NC} 4=\mathrm{CC}=\mathrm{CC}=\mathrm{C} 43) \mathrm{C}$ & \\
\hline Vanillin & $\mathrm{COC} 1=\mathrm{C}(\mathrm{C}=\mathrm{CC}(=\mathrm{C} 1) \mathrm{C}=0) \mathrm{O}$ & \\
\hline
\end{tabular}

SMILES: Simplified molecular-input line-entry system, PASS: Prediction of activity spectra of substances 


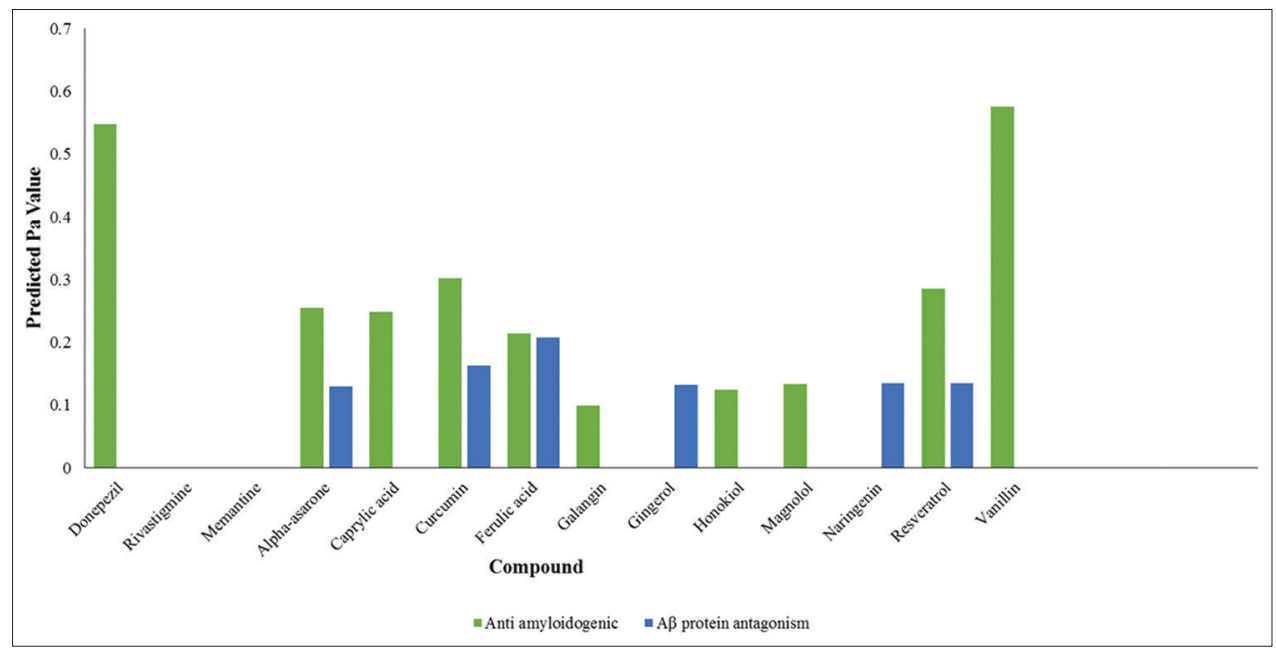

Fig. 3: Relative antiamyloidogenic activity of selected compounds

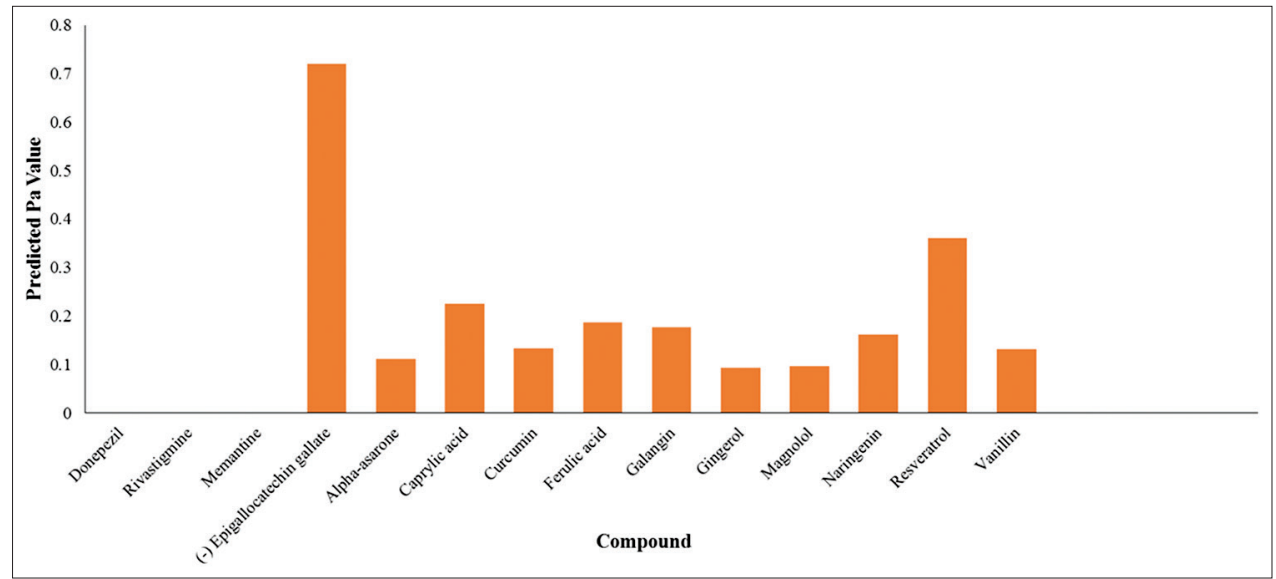

Fig. 4: Relative amyloid-beta aggregation activity of selected compounds

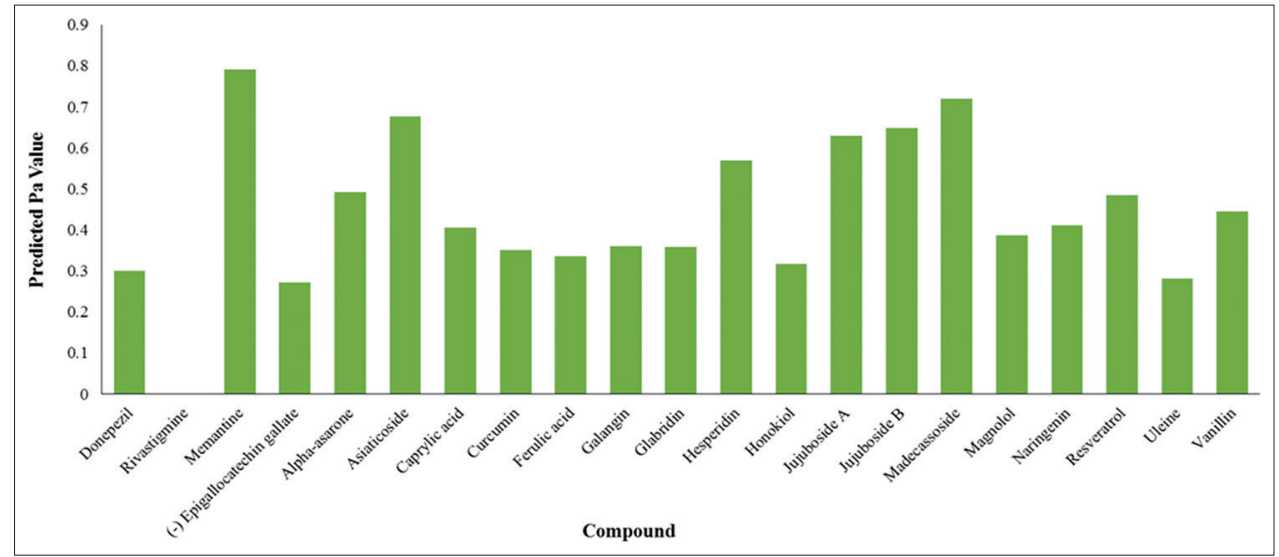

Fig. 5: Relative antidementia activity of selected compounds

PASS predictions should be used as a supplementary source of information only. However, the analysis of the compound of interest with PASS may enable the researchers to streamline the research. It can be used as a preliminary screening tool for exploring new potential drug candidates for treatment of AD.

\section{CONCLUSION}

The selected phytoconstituents have been studied using PASS prediction. This study provides a conclusive proof that the PASS predictions quite accurately coincide with the experimentally proven biological activities of the marketed drugs for treatment of AD. Previously unexplored 


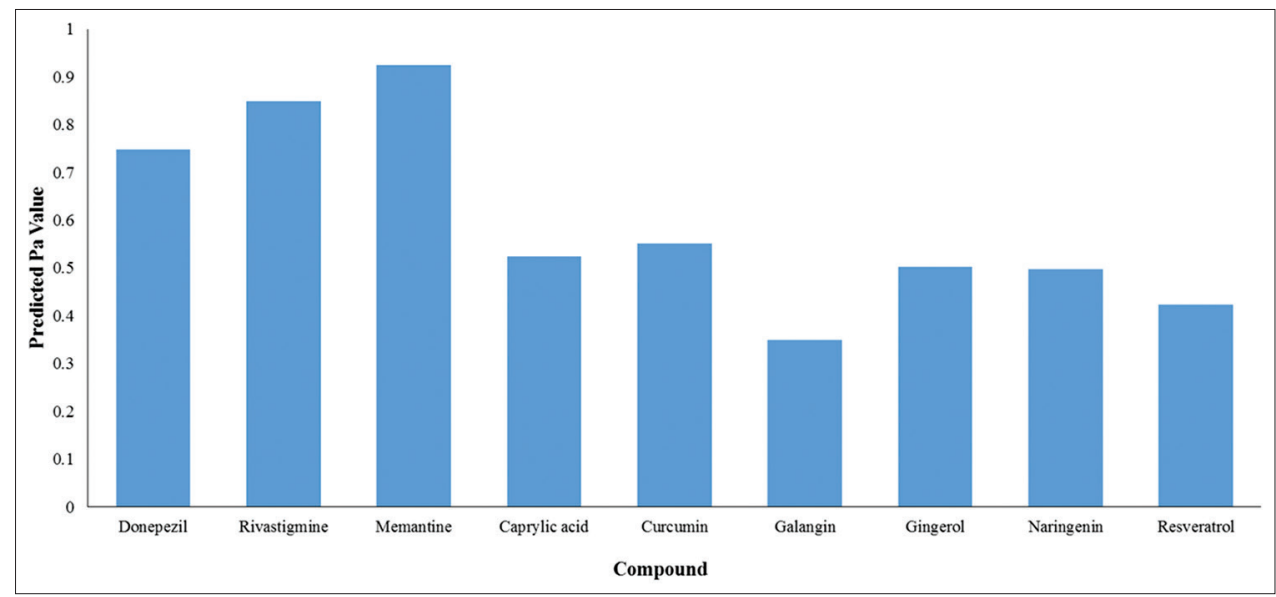

Fig. 6: Relative nootropic activity of selected compounds

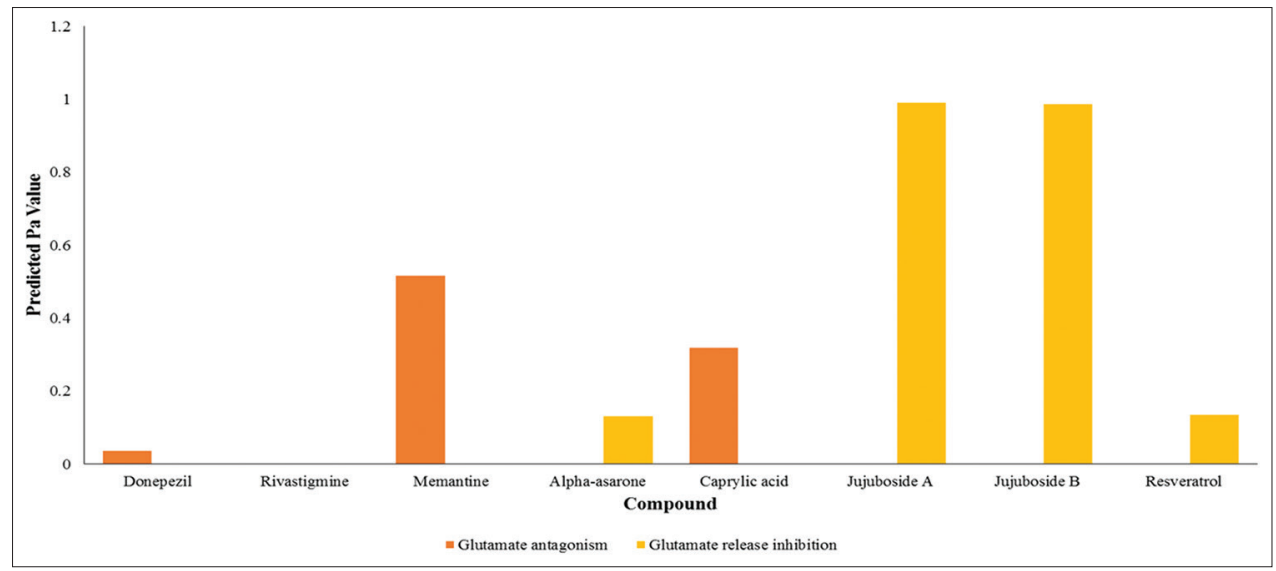

Fig. 7: Relative glutamate antagonistic activity of selected compounds

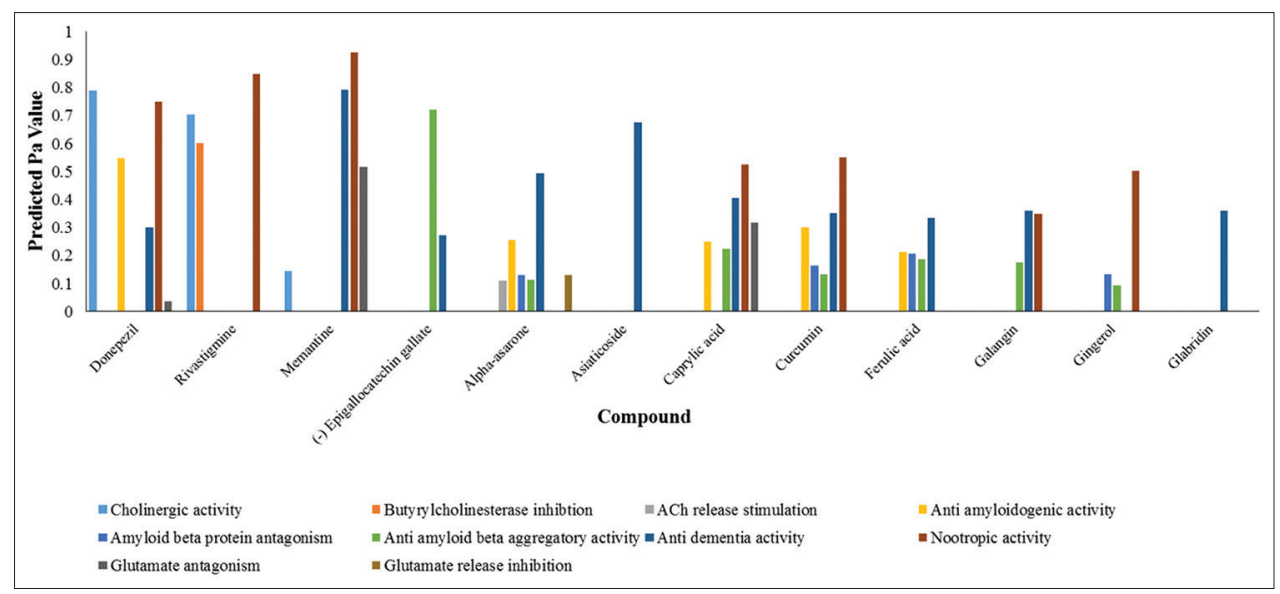

Fig. 8: An overview of prediction of activity spectra of substances predicted probable activity values for selected compounds under the six areas of pharmacological interventions for treatment of Alzheimer's disease (1/2)

but PASS predicted activities may provide the grounds for evaluation of hidden potential of the selected phytoconstituents and related analogues. In this study, highest Pa value for cholinergic activity was predicted for uleine which is comparable to the drug Mementine. Antiamyloidogenic activity and anti-A $\beta$ aggregatory activity was found to be highest in vanillin and epigallocatechin gallate, respectively, which is even more than marketed drugs. Antidementia activity was found to be highest for made cassoside, which is in close range to Mementine. Nootropic and glutamate antagonistic activity were found to be highest for curcumin and Jujuboside A, respectively. However, PASS predictions should not be taken as conclusive proofs of the existence of predicted biological activities related to the studied compounds. The predicted activities provide basis for further research avenues but the effects should be established only after significant in vivo findings.

\section{ACKNOWLEDGMENTS}

Authors would like to thank Dr. Jasneet Chawla for his support. This research did not receive any specific grant from funding agencies in the 


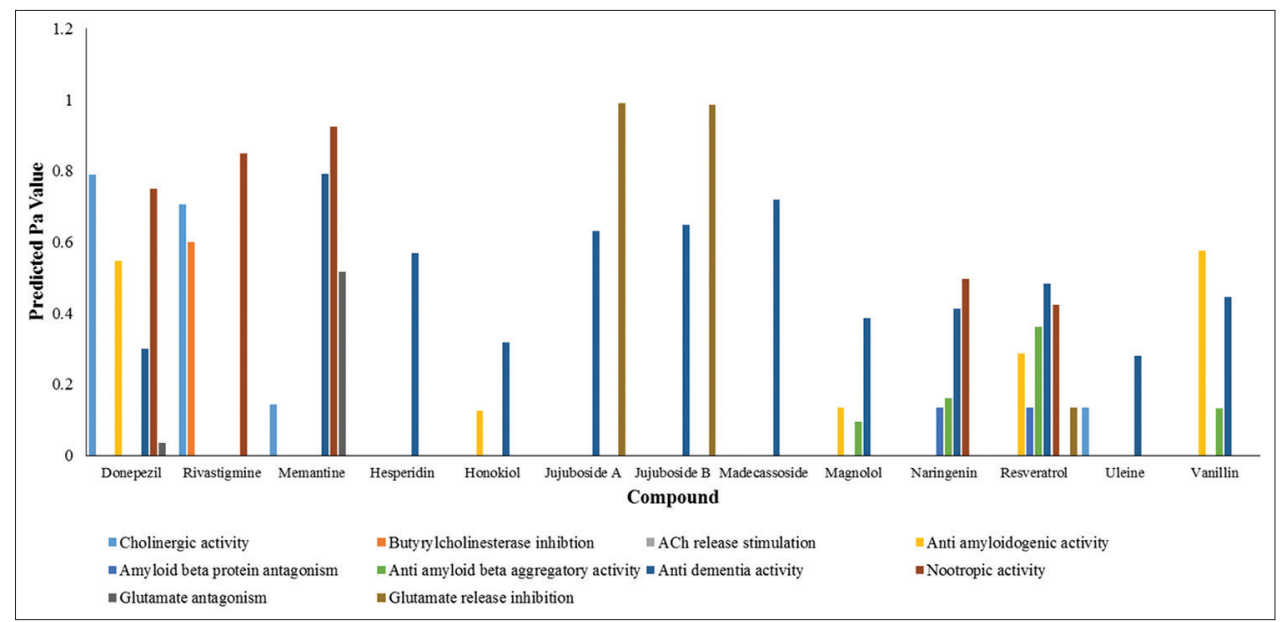

Fig. 9: An overview of prediction of activity spectra of substances predicted probable activity values for selected compounds under the six areas of pharmacological interventions for treatment of Alzheimer's disease (2/2)

public, commercial, or not-for-profit sectors. The authors declare no conflict of interest.

\section{REFERENCES}

1. World Health Organization. Dementia Fact Sheet. WHO; 2016. Available from: http://www.who.int/mediacentre/factsheets/fs362/en. [Last accessed on 2017 Apr 04].

2. Perl DP. Neuropathology of Alzheimer's disease. Mt Sinai J Med 2010;77:32-42.

3. Dwyer BE, Zacharski LR, Balestra DJ, Lerner AJ, Perry G, Zhu X, et al. Getting the iron out: Phlebotomy for Alzheimer's disease? Med Hypotheses 2009;72:504-9.

4. Centers for Disease Control and Prevention. Leading Causes of Death. CDC; 2017. Available from: https://www.cdc.gov/nchs/fastats/leadingcauses-of-death.htm. [Last accessed on 2017 Apr 04].

5. Alzheimer's Association. 2014 Alzheimer's disease facts and figures. Alzheimers Dement 2014;10:e47-92.

6. Nisbet RM, Polanco JC, Ittner LM, Götz J. Tau aggregation and its interplay with amyloid-ß. Acta Neuropathol 2015;129:207-20.

7. McGleenon BM, Dynan KB, Passmore AP. Acetylcholinesterase inhibitors in Alzheimer's disease. Br J Clin Pharmacol 1999;48:471-80.

8. Reisberg B, Doody R, Stöffler A, Schmitt F, Ferris S, Möbius HJ; Memantine Study Group. Memantine in moderate-to-severe Alzheimer's disease. N Engl J Med 2003;348:1333-41.

9. Goel RK, Singh D, Lagunin A, Poroikov V. PASS-assisted exploration of new therapeutic potential of natural products. Med Chem Res 2010;20(9):1509-14.

10. Newman DJ, Cragg GM. Natural products as sources of new drugs over the last 25 years. J Nat Prod 2007;70:461-77.

11. Rollinger JM, Stuppner H, Langer T. Virtual screening for the discovery of bioactive natural products. Prog Drug Res 2008;65:211, 213-49.

12. Dembitsky VM, Gloriozova TA, Poroikov VV. Novel antitumor agents: Marine sponge alkaloids, their synthetic analogs and derivatives. Mini Rev Med Chem 2005;5:319-36.

13. Zotchev SB, Stepanchikova AV, Sergeyko AP, Sobolev BN, Filimonov DA, Poroikov VV. Rational design of macrolides by virtual screening of combinatorial libraries generated through in silico manipulation of polyketide synthases. J Med Chem 2006;49:2077-87.

14. Habibyar AF, Sharma N, Khurana N. PASS assisted prediction and pharmacological evaluation of hesperidin against scopolamine induced amnesia in mice. Eur J Pharmacol 2016;789:385-94.

15. Marwaha A, Goel RK, Mahajan MP. PASS-predicted design, synthesis and biological evaluation of cyclic nitrones as nootropics. Bioorg Med Chem Lett 2007;17:5251-5.

16. Rezai-Zadeh K, Shytle D, Sun N, Mori T, Hou H, Jeanniton D, et al. Green tea epigallocatechin-3-gallate (EGCG) modulates amyloid precursor protein cleavage and reduces cerebral amyloidosis in Alzheimer transgenic mice. J Neurosci 2005;25:8807-14.

17. Shin JW, Cheong YJ, Koo YM, Kim S, Noh CK, Son YH, et al. A-asarone ameliorates memory deficit in lipopolysaccharide-treated mice via suppression of pro-inflammatory cytokines and microglial activation. Biomol Ther (Seoul) 2014;22:17-26.
18. Hossain S, Hashimoto M, Katakura M, Al Mamun A, Shido O. Medicinal value of asiaticoside for Alzheimer's disease as assessed using single-molecule-detection fluorescence correlation spectroscopy, laser-scanning microscopy, transmission electron microscopy, and in silico docking. BMC Complement Altern Med 2015;15:118.

19. Thaipisuttikul P, Galvin JE. Use of medical foods and nutritional approaches in the treatment of Alzheimer's disease. Clin Pract (Lond) 2012;9:199-209.

20. Mishra S, Palanivelu K. The effect of curcumin (turmeric) on Alzheimer's disease: An overview introduction curcumin and Alzheimer's disease epidemiological studies curcumin as an antiinflammatory in Alzheimer's curcumin as an anti-oxidant. Ann Indian Acad Neurol 2008;11(1):13-9.

21. Sgarbossa A, Giacomazza D, di Carlo M. Ferulic acid: A hope for Alzheimer's disease therapy from plants. Nutrients 2015;7:5764-82.

22. Guo AJ, Xie HQ, Choi RC, Zheng KY, Bi CW, Xu SL, et al. Galangin, a flavonol derived from Rhizoma Alpiniae Officinarum, inhibits acetylcholinesterase activity in vitro. Chem Biol Interact 2010;187(13):246-8.

23. Zeng GF, Zong SH, Zhang ZY, Fu SW, Li KK, Fang Y, et al. The role of 6-gingerol on inhibiting amyloid $B$ protein-induced apoptosis in PC12 cells. Rejuvenation Res 2015;18:413-21.

24. Cui YM, Ao MZ, Li W, Yu LJ. Effect of glabridin from Glycyrrhiza glabra on learning and memory in mice. Planta Med 2008;74:377-80.

25. Justin Thenmozhi A, Raja TR, Janakiraman U, Manivasagam T. Neuroprotective effect of hesperidin on aluminium chloride induced Alzheimer's disease in Wistar rats. Neurochem Res 2015;40:767-76

26. Hoi CP, Ho YP, Baum L, Chow AH. Neuroprotective effect of honokiol and magnolol, compounds from Magnolia officinalis, on beta-amyloidinduced toxicity in PC12 cells. Phytother Res 2010;24:1538-42.

27. Liu Z, Zhao X, Liu B, Liu AJ, Li H, Mao X, et al. Jujuboside A, a neuroprotective agent from semen Ziziphi Spinosae ameliorates behavioral disorders of the dementia mouse model induced by A $31-42$. Eur J Pharmacol 2014;738:206-13.

28. Mamun A, Hashimoto M, Hossain S, Katakura M. Confirmation of the experimentally-proven therapeutic utility of madecassoside in an A $\beta$ 1-42 infusion rat model of Alzheimer's disease by in silico analyses. Adv Alzheimers Dis 2015;4:37-44.

29. Ghofrani S, Joghataei MT, Mohseni S, Baluchnejadmojarad T, Bagheri M, Khamse S, et al. Naringenin improves learning and memory in an Alzheimer's disease rat model: Insights into the underlying mechanisms. Eur J Pharmacol 2015;764:195-201.

30. Li F, Gong Q, Dong H, Shi J. Resveratrol, a neuroprotective supplement for Alzheimer's disease. Curr Pharm Des 2012;18:27-33.

31. Seidl C, de Moraes Santos CA, De Simone A, Bartolini M, Weffort-Santos AM, Andrisano V. Uleine disrupts key enzymatic and non-enzymatic biomarkers that leads to Alzheimer's disease. Curr Alzheimer Res 2017;14:317-26.

32. Song S, Ma X, Zhou Y, Xu M, Shuang S, Dong C. Studies on the interaction between vanillin and $\beta$-amyloid protein via fluorescence spectroscopy and atomic force microscopy. Chem Res Chin Univ 2016;32(2):172-7. 